\title{
Rancang Bangun Aplikasi Penjualan Material Bangunan
}

\author{
Fabriyan Fandi Dwi Imaniawan \\ STMIK Nusa Mandiri Jakarta \\ fabriyan.fbf@nusamandiri.ac.id
}

\begin{abstract}
The development of information technology today is very fast and rapid, bringing so great changes in various fields. The computer which is equipment that was created to facilitate human work, when achieving progress both in making hardware and software. A building material store requires the existence of an information system that supports and provides satisfactory services for customers. At present, several companies engaged in the sale of building materials still use manual methods. Starting from recording the data of goods, the transaction process of goods, to the storage of other data related to the sales process to the making of reports. This allows for errors in recording, inaccurate reporting and delays in finding the required data. The design of this program is the best solution to solve the problems that exist in the building material store, as well as with a computerized system can achieve an effective and efficient activity in supporting sales activities.
\end{abstract}

Keywords: Program Design, Sales Application, Sales of Building Materials

\begin{abstract}
Abstrak: Perkembangan teknologi informatika saat ini sangat cepat dan pesat, membawa perubahan yang begitu besar di berbagai bidang. Adapun komputer yang merupakan peralatan yang diciptakan untuk mempermudah pekerjaan manusia, saat mencapai kemajuan baik di dalam pembuatan hardware maupun software. Sebuah toko material bahan bangunan membutukan adanya suatu sistem informasi yang menunjang dan memberikan pelayanan yang memuaskan bagi para pelanggan atau customer. Pada saat sekarang ini, beberapa perusahaan yang bergerak dalam bidang penjualan material bahan bangunan masih menggunakan caracara yang manual. Mulai dari pencatatan data barang, proses transaksi barang, sampai penyimpanan data lainnya yang berhubungan dengan proses penjualan hingga sampai pembuatan laporan. Hal tersebut memungkinkan terjadinya kesalahan dalam pencatatan, kurang akuratnya laporan dan keterlambatan dalam pencarian data yang diperlukan. Perancangan program ini merupakan solusi terbaik untuk memecahkan permasalahanpermasalahan yang ada pada toko material bahan bangunan, serta dengan sistem yang terkomputerisasi dapat tercapai suatu kegiatan yang efektif dan efisien dalam menunjang aktifitas penjualan.
\end{abstract}

Kata kunci: Perancangan Program, Aplikasi Penjualan, Penjualan Bahan Bangunan

(1) 8 (2) $\begin{aligned} & \text { This is an open access article distributed under the Creative Commons Attribution License, which permits } \\ & \text { unrestricted use, distribution, and reproduction in any medium, provided the original work is properly cited. (02019 }\end{aligned}$ by author and IJSE-Indonesian Journal on Software Engineering.

\section{A. PENDAHULUAN}

Berkembangnya teknologi saat ini yang begitu cepat, membawa perubahan yang besar di berbagai bidang. Salah satunya perekonomian. Teknologi telah membangkitkan bidang usaha dengan begitu cepat, dalam setiap kegiatan usaha dapat di topang dengan adanya teknologi yang maju. Perkembangan teknologi menjadikan ketatnya persaingan di dunia usaha. (Raharja 2017). Beberapa perusahaan yang bergerak dalam bidang penjualan material bahan bangunan, saat ini masih menggunakan sistem manual yaitu menggunakan kalkulator dan nota manual. Sehingga timbul permasalahan dalam hal efisiensi dan keefektifan pengolahan data menjadi sebuah aplikasi penjualan.

Oleh karena itu, diperlukan suatu sistem terkomputerisasi dimana komputer dapat membantu suatu pekerjaan jadi lebih efektif dan efisien. Komputerisasi merupakan pemakaian komputer sebagai alat bantu penyelesaian tugas sebagai pengganti penyelesaian pekerjaan 
secara manual. (Purwanti, 2015). Keuntungannya jika menggunakan sistem terkomputerisasi ialah lebih efisiennya waktu dalam penginputan data maupun perhitungan total penjualan tanpa harus menggunakan kalkulator maupun alat tulis. Sehingga toko dapat meningkatkan pelayanan terhadap para pelanggan.

\section{B. TINJAUAN PUSTAKA}

\section{Program}

"Program, yaitu membuat rancangan sistem yang baru dengan menggunakan bahasa pemrograman tertentu sesuai dengan aplikasi yang dibutuhkan."(Sophian, 2014).

\section{Bahasa Pemrograman}

Menurut (Raharjo, Nurhayati, \& Martono, 2015) menyatakan, "Bahasa pemrograman adalah bahasa yang dapat diterjemahkan menjadi kumpulan-kumpulan perintah dasar pemrograman.".

\section{Microsoft Visual Basic 6.0}

Menurut Subari dan Yuswanto dalam (Dewi, Kurniati, \& Irmayani, 2017),"Microsoft Visual Basic 6.0 di sebut sebagai bahasa pemrograman (language program), juga sering di sebut sebagai sarana (tool) untuk menghasilkan program-program",.

\section{Basis Data}

Menurut Sutabri dalam (V. R. Handayani et al., 2018), "Basis data (database) merupakan kumpulan data yang saling berkaitan dan berhubungan satu dengan yang lainnya, tersimpan di perangkat keras komputer dan perangkat lunak digunakan untuk memanipulasinya.".

\section{MySQL}

Menurut Faizal dan Irnawati dalam (V. R. Handayani et al., 2018), "MySQL merupakan perangkat lunak sistem manajemen berbasis data SQL (bahasa Inggris : database management system) atau DBMS yang multithread dan multi-user, dengan sekitar 6 (enam) juta instalasi di seluruh dunia."

\section{PhpMyAdmin 4.7.9}

Menurut Zaki dan Smitdev dalam (Kristania et al., 2017), "PHPMyAdmin adalah MySQL client yang berupa aplikasi web dan umumnya tersedia di server php seperti XAMPP maupun server komersial lainnya."

\section{XAMPP 3.2.2}

Menurut Wardana dalam (V. R. Handayani et al., 2018) menerangkan bahwa "XAMPP adalah paket software yang di dalamnya sudah terkandung Web Server Apache, database MySQL, dan PHP interpreter."

\section{Crystal Report 8.5}

Menurut Atmoko dalam (Dewi et al., 2017) "Crystal Report adalah komponen yang digunakan untuk membuat report atau laporan dari program yang akan dibuat, agar dapat di pahami oleh pengguna, yang di mana report tersebut di ambil dari kumpulan data dari tabel yang tersimpan di dalam database SQL Server".

\section{Waterfall}

Menurut Rosa dan Shalahuddin dalam (Supriyanta \& Nussy, 2016), "Metode waterfall sering juga disebut model sekuensial linier (sequential linear) atau alur hidup klasik (classic life cycle). Model air terjun menyediakan pendekatan alur hidup perangkat lunak secara sekuensial atau terurut dimulai dari analisis, desain, pengodean, pengujian, dan tahap pendukung" 


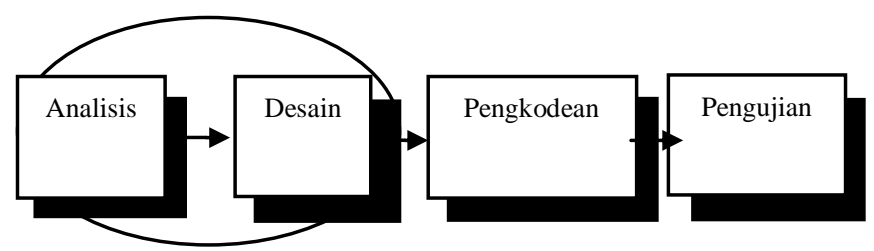

Gambar 1. Ilustrasi Model Waterfall

\section{Entity Relationship Diagram (ERD)}

Menurut Ladjamudin dalam (Destiana et al., 2014), "ERD adalah suatu model jaringan yang menggunakan susunan data yang disimpan dalam sistem secara abstrak. Jadi, jelaslah bahwa ERD ini berbeda dengan DFD yang merupakan suatu model jaringan fungsi yang akan dilaksanakan oleh sistem, sedangkan ERD merupakan model jaringan data yang menekankan pada struktur- struktur dan relationship data"

\section{Logical Record Structure (LRS)}

Menurut Hasugian dan Shidiq dalam (Handayani et al.,2017) memberikan batasan bahwa LRS adalah "sebuah model sistem yang digambarkan dengan sebuah dagram-ER akan mengikuti pola atau aturan pemodelan tertentu dalam kaitannya dengan konvemsi ke LRS."

\section{Flowchart}

Menurut (John \& Hansun, 2017) menyatakan: "Flowchart merupakan suatu bagan yang menggambarkan urutan proses secara detail dan hubungan antara suatu proses dengan proses yang lain dalam suatu program, dimana pada flowchart juga terdapat simbol-simbol yang memiliki fungsinya masing-masing."

\section{METODE PENELITIAN}

Metode yang digunakan dalam pembuatan aplikasi ini adalah dengan metode waterfall menurut Rosa dan Shalahudin dalam (Supriyanta \& Nussy, 2016) yang dibagi menjadi lima tahapan, yaitu:

\section{Analisis kebutuhan perangkat lunak}

Proses pengumpulan kebutuhan dilakukan secara intensif untuk menspesifikasikan kebutuhan perangkat lunak agar dapat dipahami perangkat lunak seperti apa yang dibutuhkan oleh user. Spesifikasi kebutuhan perangkat lunak pada tahap ini perlu untuk didokumentasikan supaya proses identifikasi mudah dipahami.

\section{Desain}

Proses multi langkah yang fokus pada desain pembuatan program perangkat lunak termasuk struktur data, arsitektur perangkat lunak, representasi antarmuka, dan prosedur pengodean. Tahap ini mentranslasi kebutuhan perangkat lunak dari tahap analisis kebutuhan ke representasi desain agar dapat diimplementasikan menjadi program pada tahap selanjutnya. Desain perangkat lunak yang dihasilkan pada tahap ini juga perlu didokumentasikan. Desain database menggunakan Logical Record Structure (LRS) dan Entity Relationship Diagram (ERD).

3. Pembuatan Kode Program

Pada tahap ini merupakan pembuatan kode program yaitu desain harus ditranslasikan ke dalam program perangkat lunak menggunakan bahasa pemrograman yang bisa dikenal oleh komputer. Aplikasi yang digunakan yaitu Microsoft Visual Basic 6.0 dan menggunakan database MySQL.

\section{Pengujian}

Pada tahap ini berfokus pada perangkat lunak secara logik dan fungsional dan memastikan bahwa semua bagian sudah diuji. Hal ini dilakukan untuk meminimalisir kesalahan(error) dan memastikan keluaran yang dihasilkan sesuai dengan yang diinginkan. Pengujian ini menggunakan Black box Testing. 


\section{Pendukung (support) atau pemeliharaan (maintenance)}

Perangkat lunak mengalami perubahan ketika sudah dibuat dan dikirimkan ke user, yang terjadi karena adanya kesalahan-kesalahan yang tidak terdeteksi sewaktu perangkat lunak beradaptasi dengan lingkungan baru.

D. HASIL DAN PEMBAHASAN

1. Analisis Kebutuhan:

a. Kebutuhan pengguna

1) Kasir

Data barang, penjualan maupun pembelian barang.

2) Pemilik toko
a) Data admin
Untuk mengetahui siapa saja yang menggunakan program penjualan bahan bangunan.
b) Laporan pembelian dan laporan penjualan harian, bulanan maupun tahunan.

b. Kebutuhan pengolahan data

1) Back up data, untuk menanggulangi saat terjadinya kehilangan data pada database.

2) Cetak data, sebagai bukti nyata data keluaranyang telah melalui proses.

c. Kebutuhan system

1) Hak akses

a) Super admin.

(1) Back up data yang dilakukan secara berkala.

(2) Dapat menambah maupun menyimpan data admin.

(3) Dapat menambah maupun menyimpan data barang.

b) Admin, dapat mengakses seluruh program kecuali data admin dan data barang.

2) Sistem keamanan
a) Login, setiap akan masuk ke dalam aplikasi diharuskan login terlebih dahulu pada form login.
b) Enkripsi data sandi.

d. Hardware dan Software

1) Hardware (perangkat keras) merupakan komponen yang terlihat secara fisik dalam pengolahan data. Perangkat keras yang digunakan meliputi:

Satu perangkat komputer
a) $\mathrm{CPU} \quad$ : Pentium 4
b) RAM : :1 GB (minimum)
c) Harddisk : $320 \mathrm{~GB}$
d) Monitor : :14"
e) Mouse : :PS/2
f) Keyboard : :108 keys
g) Printer : Epson Stylus T13

2) Spesifikasi software (perangkat lunak) yang dibutuhkan guna mendukung aplikasi yang akan dibangun yaitu:
a. Microsoft Visual Basic 6.0
b. MySQL
c. PhpMyAdmin Versi 4.7.9
d. XAMPP Versi 3.2.2
e. ODBC (Open Database Connectivity) Versi 5.3.4
f. Crystal Report Versi 8.5
g. Browser yang digunakan Internet Explorer 


\section{Implementasi}

Implementasi rancangan antar muka pada aplikasi penjualan bahan bangunan

a. Halaman Login

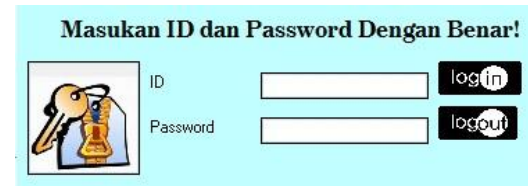

Gambar 2. Halaman Login

b. Halaman Menu Utama

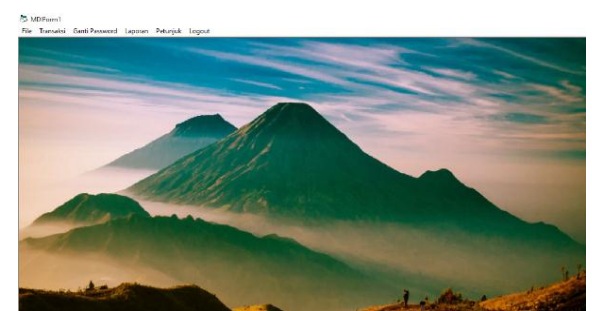

Gambar 3. Halaman Menu Utama

c. Halaman Admin

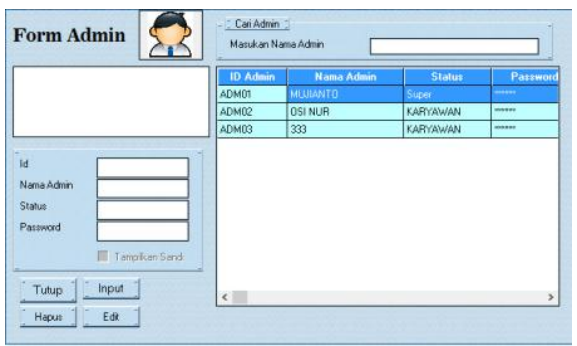

Gambar 4. Halaman Admin

d. Halaman Barang

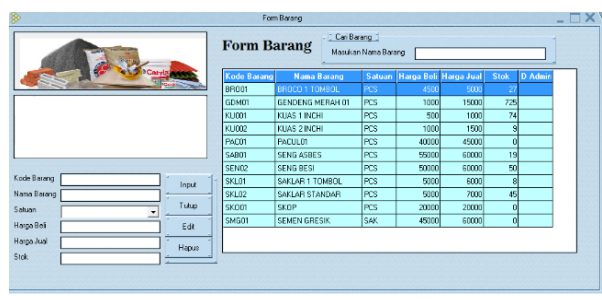

Gambar 5. Halaman Barang

e. Halaman Transaksi

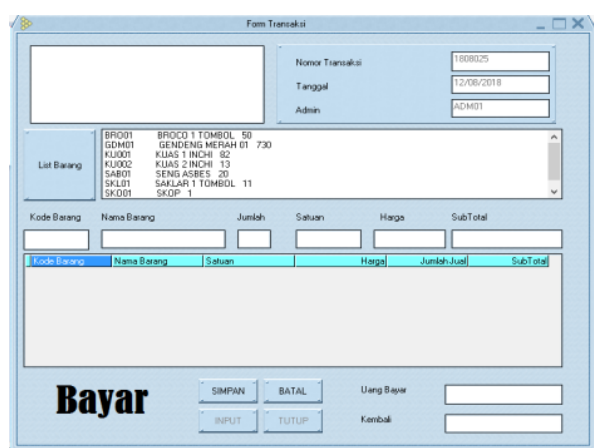

Gambar 6. Halaman Transaksi 
f. Halaman Ganti Password

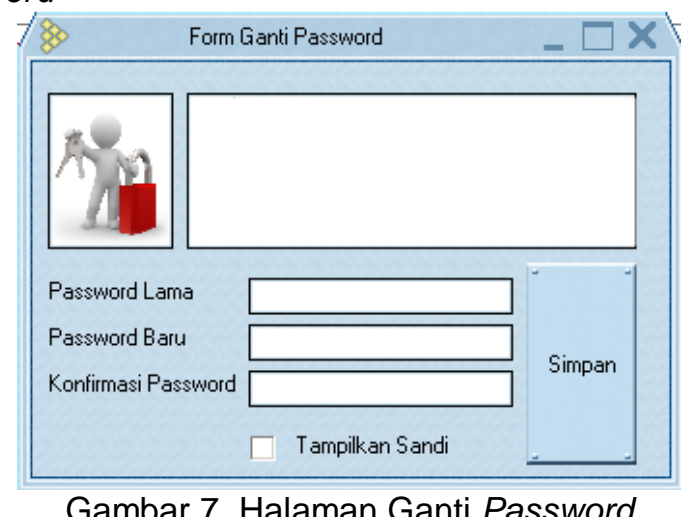

Gambar 7. Halaman Ganti Password

g. Halaman Laporan

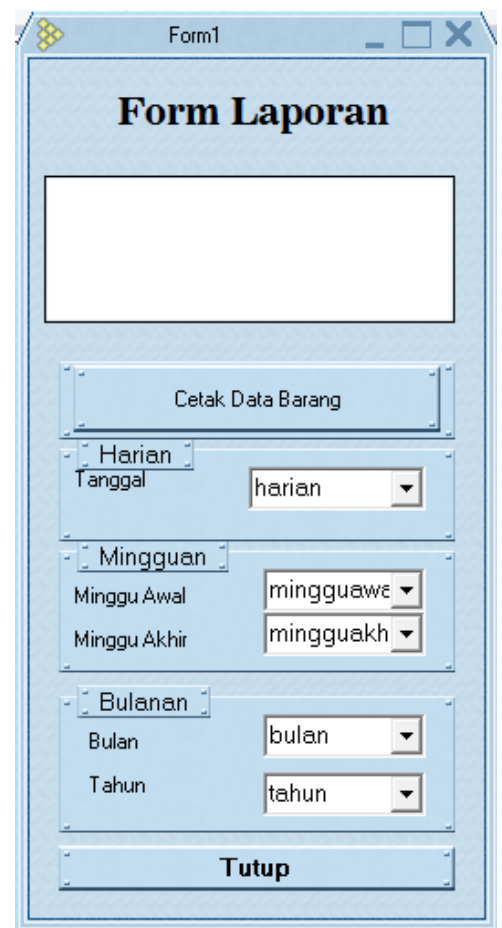

Gambar 8. Halaman Laporan

h. Halaman Petunjuk

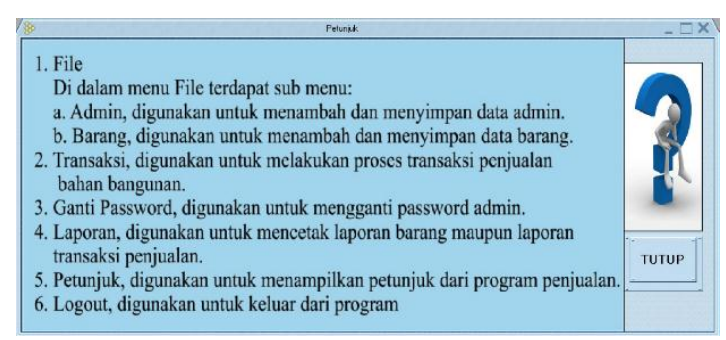

Gambar 9. Halaman Petunjuk 


\section{Entity Relationship Diagram (ERD}

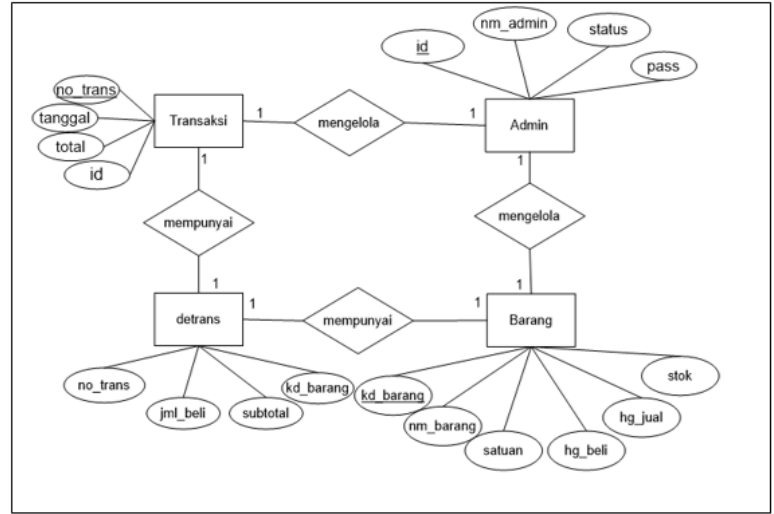

Gambar 10. Entity Relationship Diagram

\section{Logical Record Structure (LRS)}

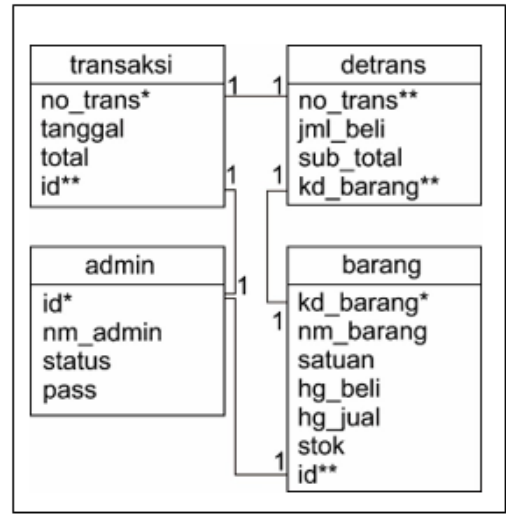

Gambar 11. Logical Record Structure

\section{Flowchart}

a. Flowchart Login

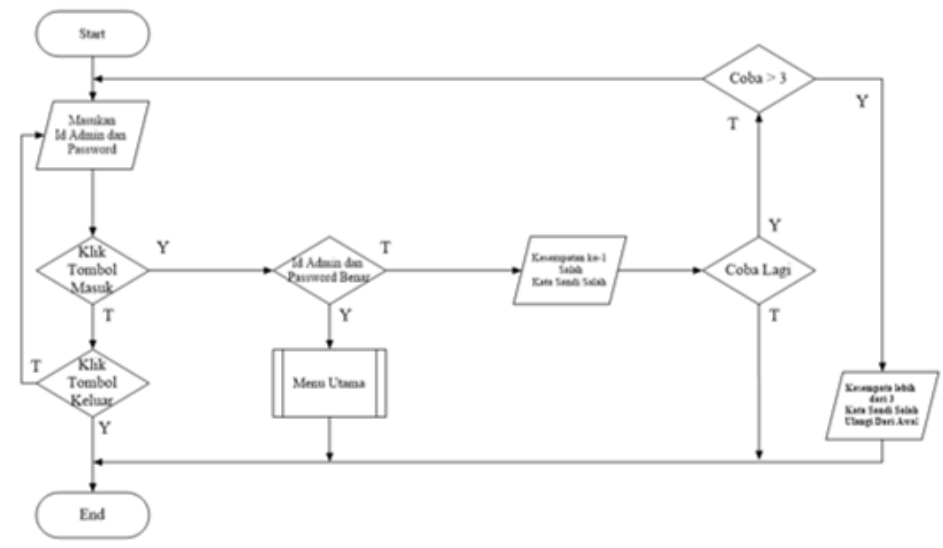

Gambar 12. Flowchart Login 
b. Flowchart Menu Utama

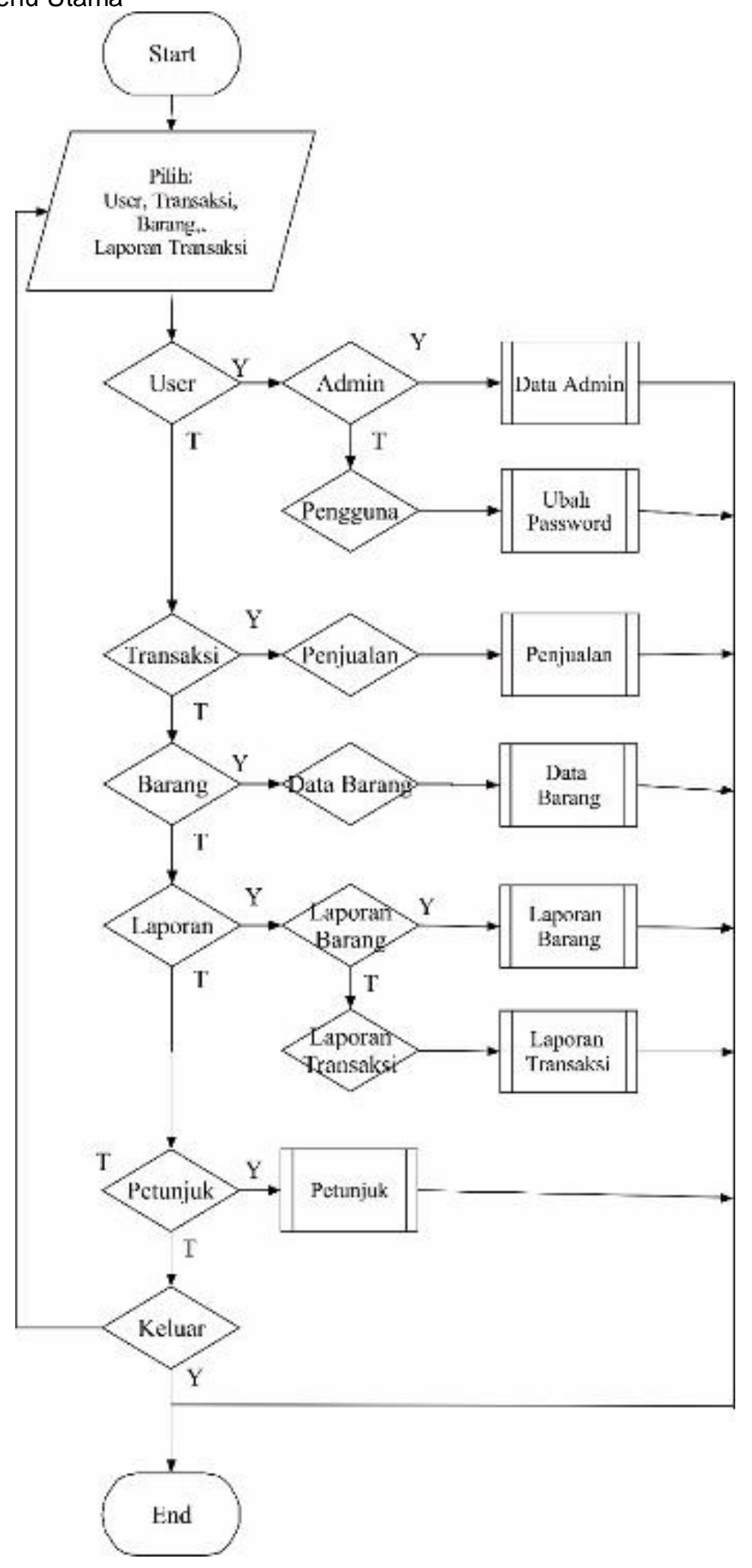

Gambar 13. Flowchart Menu Utama 
c. Flowchart Admin

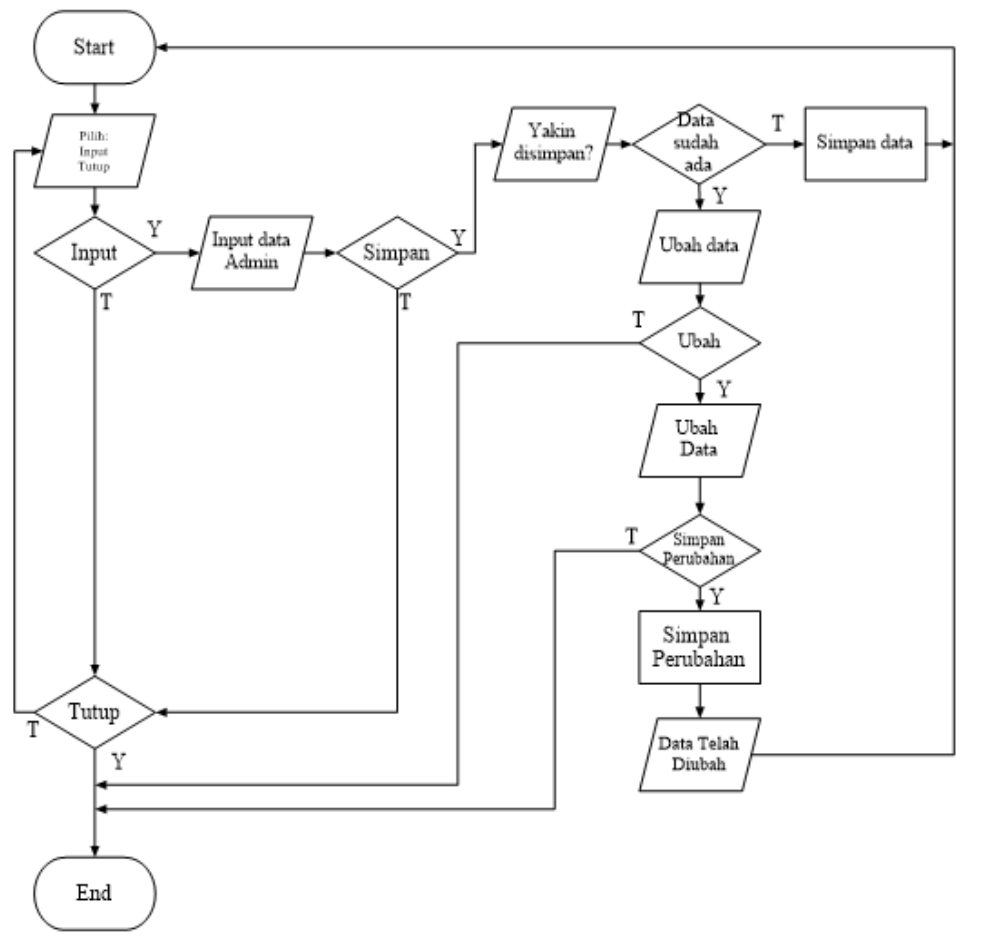

Gambar 14. Flowchart Admin untuk menambah data admin

d. Flowchart Barang

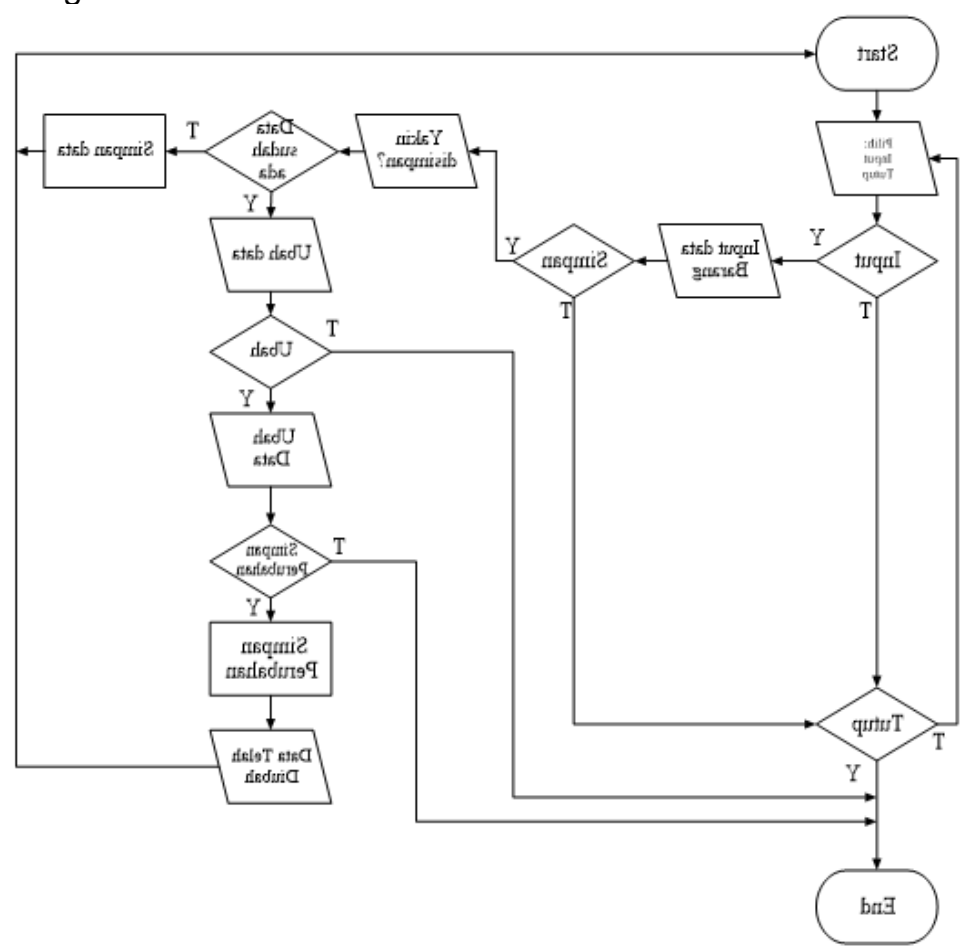

Gambar 15. Flowchart Barang 
e. Flowchart Transaksi

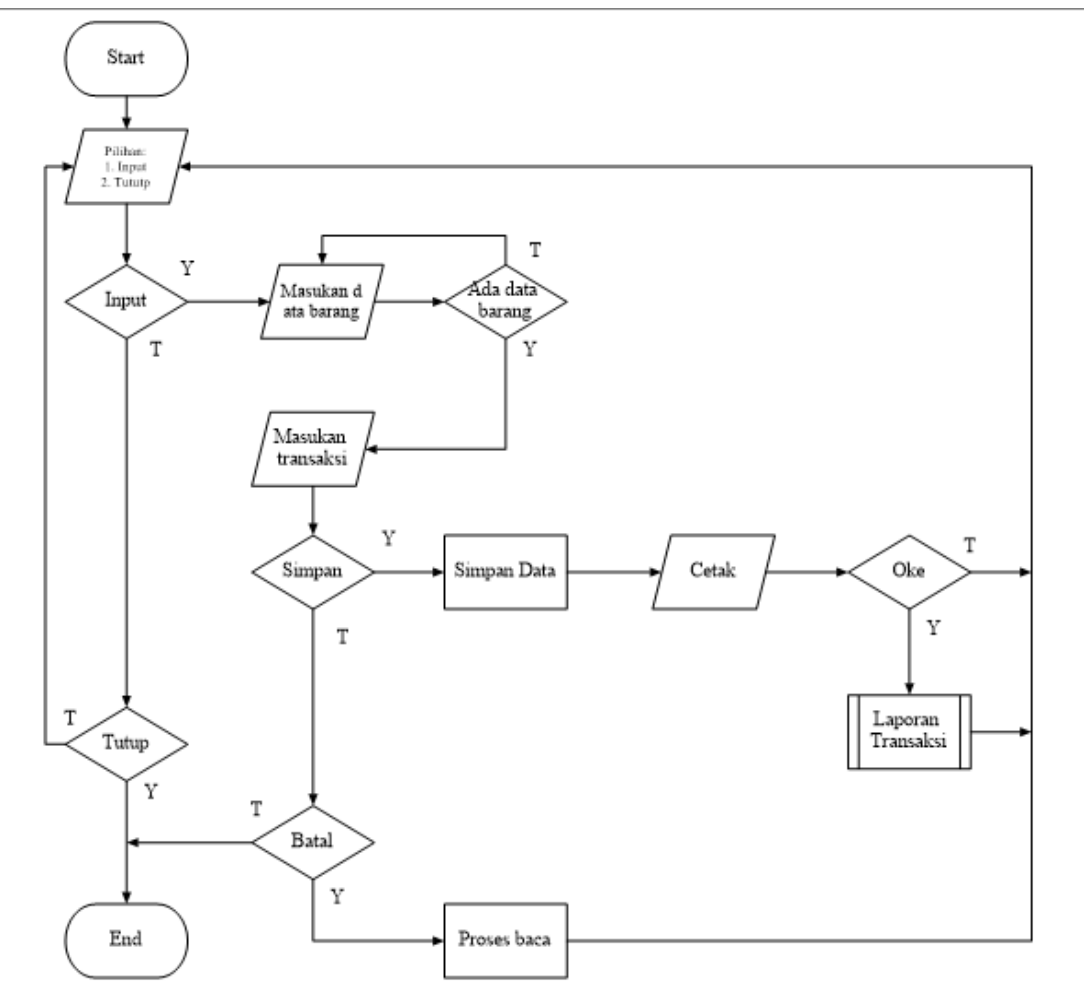

Gambar 16. Flowchart Transaksi

\section{f. Flowchart Laporan}

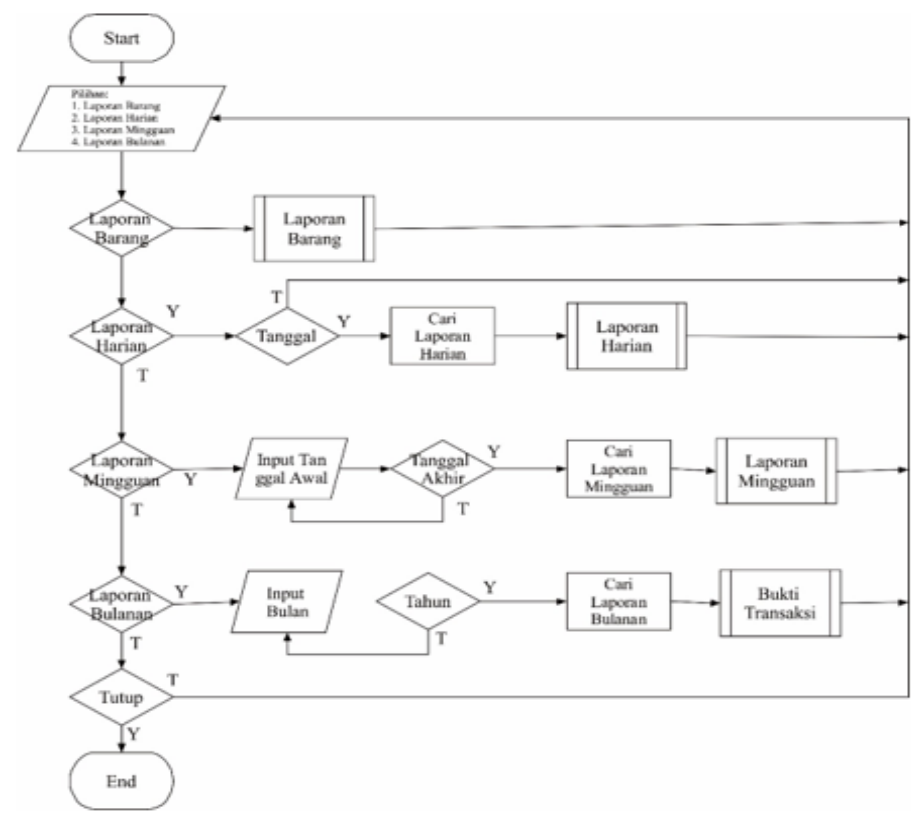

Gambar 17. Flowchart Laporan 
g. Flowchart Ganti Password

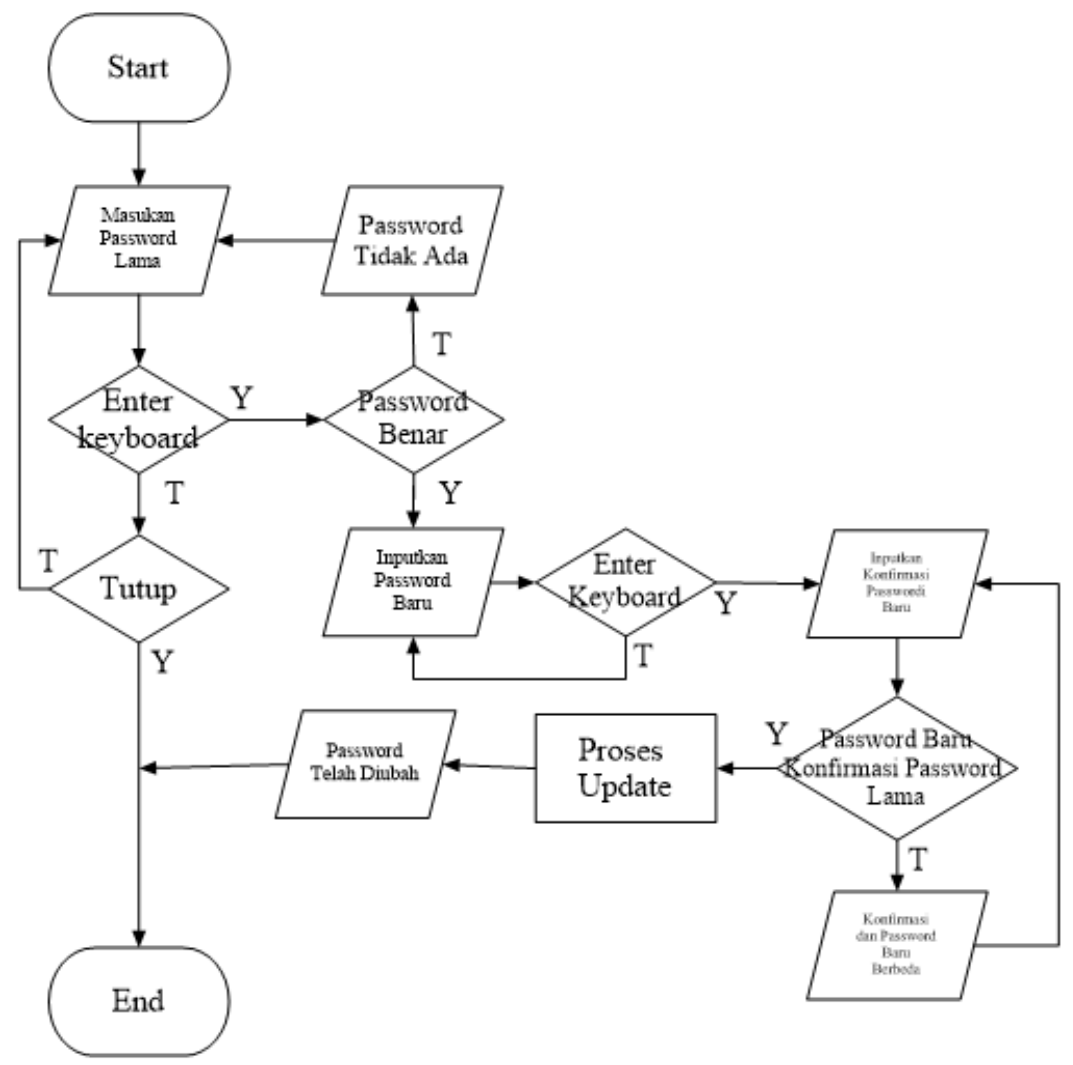

Gambar 18. Flowchart Ganti Password

\section{E. KESIMPULAN}

1. Dengan adanya aplikasi ini dapat meningkatkan efisien dan efektifnya proses penjualan bahan bangunan.

2. Menyimpan data dalam jumlah yang lebih banyak dan waktu yang lebih lama dengan aman dan terjamin karena menggunakan id dan password.

3. Mengawasi jalannya proses transaksi.

4. Terhindar dari kerangkapan data dikarenakan kode yang dimasukan memiliki karakteristik tersendiri serta memberikan kemudahan dalam menambah data, mengolah data, mencari data, pencetakan data dan pembuatan laporan yang diperlukan.

\section{REFERENSI}

Destiana, H., Studi, P., Akuntansi, K., Fajrin, F., Studi, P., \& Informasi, S. (2014). Sistem Informasi Penjualan Barang Berbasis Web Pada PT. Catur Daya Persada Jakarta Keywords : Sales Product, Information, Catur Daya Persada, XVI(2), 32-43.

Dewi, M. A., Kurniati, D., \& Irmayani, W. (2017). Aplikasi Pelayanan Jasa Persediaan bahan Baku Pada Laundry Q Pontianak, V(2), 112-117.

Elistri, M., Wahyudi, J., \& Supardi, R. (2014). Penerapan Metode SAW Dalam Sistem Pendukung Keputusan Pemilihan Jurusan Pada Sekolah Menengah AtasNegeri 8 Seluma, 10(2), 105-109.

Febriani, A., \& Hidayati, N. (2017). Penerapan Aplikasi Program Penjualan Dan Pembelian Menggunakan Model Rapid Application Development. Jurnal Informatika, 4(2), 261-271. 
Handayani, P., Septiana, S., Moh, K. H., Su, S., Al, M. A., \& Pertemuan, M. A. Z. (2017). Aplikasi Penerimaan Dana Bantuan Guru Ngaji dan Marbot Masjid Bazis Kota Administrasi Jakarta Timur Berbasis Web, 4(2), 25-31.

Handayani, V. R., Wijianto, R., Anggoro, A., Informatika, M., Informasi, S., \& Informatika, M. (2018). Sistem Informasi Pendaftaran Seleksi Kerja Berbasis Web Pasa BKK (Bursa Kerja Khusus) Tunas Insan Karya SMK Negeri 2 Banyumas, 6(1), 76-84.

John, R., \& Hansun, S. (2017). Rancang Bangun Aplikasi Prediksi Penjualan Menggunakan Algoritma Double Exponential Smoothing Berbasis WEB, 14(1), 28-35. https://doi.org/10.9744/informatika.14.1.28-35

Kristania, Y. M., Maryani, I., Asyifudin, I., Informasi, S., Informasi, S., \& Informatika, M. (2017). Sistem Informasi Akademik Berbasis WEB Pada SMK Negeri 2 Banyumas. Jurnal Evolusi, 5(2), 82-89.

Muzid, S., Studi, P., Informasi, S., Teknik, F., Kudus, U. M., Latifah, N., ... Kudus, U. M. (2015). Pemanfaatan SMS Gateway Multi Direct Untuk Penyebaran Informasi Desa Melalui Sistem Layanan Informasi Desa, 6(2), 415-420.

Panggabean, T. E. (2018). Penerapan Sistem Berbasis Web Dalam Penerimaan Murid Baru Pada SMA Markus Medan, 5(2), 130-135.

Paulina, D., Berahmana, S., Times, A., \& Roman, N. (2015). ( 1 ) )" Nyalon Yukk " A plikasi Informasi Salon Kecantikan berbasis Android, 1(1), 669-680.

Purwanti, Endang (2015). Perancangan Sistem Komputerisasi Penggajian Guru (Pada Smk Gajah Mada 01 Margoyoso). Prosiding KMSI 2015, 39-44.

Raharja, S. (2017). Implementasi Kriptografi Algoritma AES Serta Algoritma Kompresi Huffman Dengan Menggunakan Pemograman PHP, 225-230.

Raharjo, S. M., Nurhayati, O. D., \& Martono, K. T. (2015). Sistem Informasi Pencatatan Data Warga Kelurahan Berbasis Mobile. Jurnal Teknologi Dan Sistem Komputer, 3(3), 399.

Setiawan. (2014). Sistem Administrasi Rawat Jalan Pada Klinik Siliwangi, 2(1), 76-97.

Sophian, S. (2014). Pengimplementasian Dan Perancangan Sistem Informasi Penjualan Dan Pengendalian Stok Barang Pada Toko Swastika Servis (SS) Bangunan Dengan Menggunakan Bahasa Pemrograman Visual Basic 6.0 Didukung Dengan Database MySQL. Jurnal Momentum, 16(2), 34-44.

Supriyanta, \& Nussy, E. (2016). Microsoft Word - 03 Perancangan Website Sebagai Media Informasi Panti Asuhan Batu Penjuru Kulon Progo, 8(2), 17-22. 